\title{
Effects of Group Counseling
}

\section{An Experiment Evaluated by Objective Tests}

EARL D. Douglas

Staff Clinical Psychologist, Child Study Institute, Lucas County Family Court

Center, Toledo, Ohio

Counselor, 1956-57, Booker T. Washington High School, Marlin, Texas;

Personnel Psychologist Assistant, 1957-59, U.S. Army

B.A. (Psychology), 1954, Texas Southern University; M.A. (Psychology), 1956, George Pepperdine College

David FIRE

Family Counselor, Domestic Relations Division, Lucas County Family Court Center, Toledo, Ohio

Probation Counselor, 1959-63, Juvenile Division, Lucas County Family Court Center

A.B. (Sociology), 1959, Manchester College; M.S.W., 1964, University of Michigan

ERvin J. Wierzbinski

Administrative Assistant, Lucas County Family Court Center, Toledo, Ohio Counselor, 1955-56, Indiana State Prison, Michigan City

B.A. (Sociology), 1953, M.A. (Correctional Administration), 1957, University of Notre Dame; M.S.W., 1963, University of Michigan

Staff members of the Lucas County (Toledo, Ohio) Family Court Center became concerned because it seemed that while diagnosis of delinquent behavior was leaning toward an individualized, differential technique, treatment methods were not correspondingly developed. The traditional one-to-one interview was often ineffective. In an effort to find useful alternative methods, several staff members who had participated in a group therapy experience themselves and had received in-service training in group methods decided to experiment. On the basis of prior social and psychological studies, six juvenile probationers were selected to participate in a series of group counseling sessions.

To measure the effectiveness of group therapy in rehabilitating these probationers, objective tests were administered at the beginning and again at the end. Positive changes were noted in all of the probationers. The test results revealed those attitudes and habits that seem to be modifiable through group counseling. Further use of such tests may prove valuable in the selection of probationers who may most benefit from such a technique. 
A PROJECT RECENTLY UNDERTAKEN by the clinical services department (three psychologists and one part-time consulting psychiatrist) and six members of the counseling staff of the Lucas County (Toledo) Juvenile Court was designed to test the effect of group counseling in changing the attitudes and behavior patterns of selected juvenile probationers living in their own homes or in foster homes in the community. Each worker in this experiment had participated in the Family Court Center's in-service training group therapy program, which was begun in 1957 and is conducted by Dr. Henry L. Hartman, psychiatric consultant to the Lucas County Family Court.

The experiment was carried out without the benefit of any special grants or funds. ${ }^{1}$

Participation of the workers and probationers was voluntary. However, once a probationer chose to participate in the experiment, attendance was made mandatory as a condition of his probation.

We hypothesized that group counseling can effectively change the attitudes and behavior patterns of certain juvenile probationers by helping them gain an understanding of their personal and family problems. Sharing their experiences with peers would show them that others have similar problems; this discovery, in itself, would be therapeutic. We also hy-

$1 \mathrm{We}$ are, however, indebted to Judge Paul Alexander and L. Wallace Hoffman, director of the Family Court Center, for providing us with encouragement and the space in which we met. We also wish to express our appreciation to Ruth Williams, chief psychologist at the Family Court Center, who served as director of this experiment and helped in the preparation of this article. Dr. Hartman served as consultant during the experiment. pothesized that group counseling would enable a counselor to work with a larger number of cases and thus meet the ever increasing demand for his services.

\section{Selection and Organization}

Four groups in all were chosen. The group evaluated here was composed of six probationers, two leaders, and an observer-recorder. The boys had been on probation for periods varying from two months to nearly two years and were selected for participation in the experiment on the basis of similarities in age, IQ, school grade, and ability or potential ability to respond to group counseling. They were fifteen or sixteen years old and in the eighth, ninth, or tenth grade. The IQ range was 90 to 124 . The types of offenses committed by these boys varied.

Any boy who was thought to have a character disorder or an acting-out tendency that might be detrimental to the group was excluded. Final decision on selection of a probationer was based on the judgment of at least one group leader who had had personal contact with him. Some probationers who qualified for the experiment had to be excluded because of transportation problems.

In an attempt to discover whether changes in attitude that had been effected by group counseling could be measured by an objective test, each probationer was given the Gordon Personal Inventory and the Gordon Personal Profile ${ }^{2}$ at the beginning of the experiment and at the end.

The content of the group meetings

2 L. V. Gordon, Gordon Personal Profile (New York: World Book Company, 1953). and Gordon Personal Inventory (New York: World Book Company, 1956). 
was confidential, with one exception necessitated by the legal setting in which we function, our positions within the setting, and our obligations to the community and the court: any law violation, brought out in a group discussion, which had not been previously cleared would be discussed privately between the probationer and the leader after the group meeting. The group members knew this in advance; none of them ever had to be called upon to explain any such violations.

This group met for just over eight calendar months in twenty-eight ninety-minute weekly meetings. The average attendance of the six-member group was 4.3. Near the middle of June, at the end of the school year, the group terminated rather spontaneously. Several of the members were planning to be out of town during the summer months.

The meetings were devoted entirely to discussion and the approach was nondirective, but during the last few sessions we found it helpful to reintroduce some topics that had been discussed in previous meetings.

\section{The Boys}

Following is a brief summary of the problems of the probationers in this group and the treatment goals for each one:

Fifteen-year-old Robert $T$. lived with his mother and adoptive father in a middle-class neighborhood. $\mathrm{He}$ had an IQ of 124 and was a sophomore in a vocational high school. Robert had been referred to the juvenile court twice for well-planned and wellexecuted burglaries. There was a considerable amount of parental disharmony in his home. Both parents lacked understanding of his needs. His adoptive father was inclined to be demanding and punitive. His mother, although closer to Robert, was weak, ineffectual, and completely unsuccessful in her efforts to bring him and his adoptive father together. Treatment goals for Robert were (1) to offer him support so that he might more easily tolerate home conditions and (2) to give him an outlet for his hostilities so that he could devote more of his energy to education, since he had such an excellent potential.

James C., sixteen years old, lived with his parents in a working-class neighborhood. He had an IQ of 115 and was a junior in a regular high school program. James had been referred to court for engaging in incestuous relations with his sister. Contributing factors were an alcoholic father and a cold and undemonstrative mother; with both, his relationship was negative. He was withdrawn and shy among his peers. Treatment goals were (1) to increase his ability to enjoy satisfactory social relationships and (2) to give him some interpretation of normal parent-child relationships so that he could at least understand if not develop them.

Michael K., a fifteen-year-old freshman in high school with an IQ of 105 , lived with his parents in a workingclass neighborhood. He had been referred to court on a charge of breaking and entering. Michael's father was completely indifferent to him, and his mother, in an attempt to compensate, was overindulgent and reluctant to give Michael any responsibility. He was withdrawn socially and tended to associate with younger boys. Treatment goals were (1) to give him an opportunity to interact more with boys of his own age, (2) to 
help him recognize his immaturity, and (3) to help him develop a sense of responsibility.

Fifteen-year-old Vernon L. lived with his mother and father in a working-class neighborhood, was a freshman in high school, and had an IQ of 90. He was on probation for stealing a large sum of money from his father, who had been committed to the State Hospital on two occasions but was at home at the beginning of the group meetings. The father was highly unstable and fluctuated between periods of rage and periods of cheerfulness. Vernon's mother tried hard to make up for his father's inadequacies. Vernon was afraid he was going to "turn out like his dad"; he was ashamed of and constantly upset by his father's condition. Treatment goals were (1) to guide him toward a more realistic view of his home situation and his position in it and (2) to give him an opportunity to develop social skills in an accepting group climate.

Stanley T., a fifteen-year-old only child, lived with his mother in an apartment in a working-class neighborhood. Although he had normal mental ability (IQ 101) he was only in the eighth grade because of a previous failure. His offenses included auto theft and burglaries. Stanley had never known his father. He knew only what his mother told him and from this he said he "hated" him. His relationship to his mother was close. However, because his mother had to work to support them, he had a good deal of free unsupervised time. He was drawn into an aggressive group of boys, apparently to fulfill his need for companionship, especially male companionship. Treatment goals were (1) to strengthen his social and moral standards and (2) to provide him with support and encouragement for building friendships with nondelinquent boys.

Terry G., fifteen years old, lived with his parents in a middle-class neighborhood. He was a sophomore in high school and had an IQ of 98. His only offense was larceny (pickpocketing) but he had a recent record of truancy and faced an additional referral if this did not stop. Terry's basic conflict was the fact that both his older siblings were doing well in college while he had difficulty maintaining passing grades in high school. Although his parents tried to understand, they made frequent comparisons which upset him. Low grades kept Terry from playing football; he also felt shunned by the "better crowds" for the same reason. Treatment goals were (1) to improve his attitude toward himself and school and (2) to help him acquire a more realistic view of his future.

\section{Evaluation}

To evaluate the success of the group as a whole and as a means of achieving individual treatment goals we used the Gordon Personal Inventory and Profile and also the "swivel chair" approach, discussing the sub. jective content of meetings as it applied to individual progress or lack of it.

The Gordon tests are rather brief, forced-choice procedures which rate adjustment in eight areas: Ascendancy, Responsibility, Emotional Stability, Sociability, Cautiousness, Original Thinking, Personal Relations, and Vigor. The combined results, showing progress or lack of progress in each of these categories for each member of the group, are given in Table 1. 
TABLE 1

Per Cent of Net Gain or Loss in Traits Measured, Individual and Group

\begin{tabular}{|c|c|c|c|c|c|c|c|c|}
\hline & $\mathbf{A}$ & $\mathbf{R}$ & ES & $\mathrm{s}$ & C & OT & PR & V \\
\hline $\begin{array}{l}\text { Robert } \mathbf{T} . \\
\text { James C. } \\
\text { Michael } \mathbf{K} . \\
\text { Vernon } \mathbf{L} . \\
\text { Stanley } \mathbf{P} . \\
\text { Terry G. }\end{array}$ & $\begin{array}{l}+18 \\
+56 \\
+2 \\
+6 \\
+18 \\
+72\end{array}$ & $\begin{array}{l}+21 \\
+26 \\
+14 \\
+27 \\
-6 \\
-27\end{array}$ & $\begin{array}{r}+16 \\
+17 \\
+27 \\
+7 \\
-11 \\
0\end{array}$ & $\begin{array}{l}+30 \\
+31 \\
+\quad 3 \\
+11 \\
-76 \\
+40\end{array}$ & $\begin{array}{l}+49 \\
+35 \\
+18 \\
+60 \\
-24 \\
-39\end{array}$ & $\begin{array}{l}+19 \\
+6 \\
+6 \\
-11 \\
-18 \\
-83\end{array}$ & $\begin{array}{r}+6 \\
+34 \\
-3 \\
+38 \\
-49 \\
-21\end{array}$ & $\begin{array}{l}+19 \\
+5 \\
+14 \\
+8 \\
+43 \\
+71\end{array}$ \\
\hline Total & +172 & +55 & +22 & +17 & +99 & $\overline{-81}$ & $\overline{+5}$ & +18 \\
\hline
\end{tabular}

As shown in the table, four of the six boys-Robert, James, Michael, and Vernon-improved noticeably in the traits measured by the tests taken at the beginning and end of the experiment. The regression or lack of progress of Stanley and Terry may be attributable to several factors relating to group selection or composition. For the group as a whole there were gains in all traits except original thinking. However, since this category measures nonconformity, this finding may not be an undesirable one in the light of our goals.

Following is our subjective evaluation and summary of the negative and positive aspects of the experiment.

\section{Negative Aspects}

As the group began to gain cohesiveness, we found that we had made one or two errors in selection; certainly we had used poor judgment in selecting Stanley. The fact that he was only an eighth grader, while all the other members were in high school, interfered with his acceptance and participation in group discussions. This was clearly shown when Stanley was asked what school he attended. He attempted to avoid answering the question by saying, "Oh, you wouldn't know it, it's just a little school." The boy who had posed the question insisted on an answer, and Stanley finally told him when it was clear he wouldn't be able to avoid it. He never talked much during the group sessions. The drop in his sociability rating on the Gordon Test may have been partly caused by this negative group experience. On the other hand, it may have meant that Stanley was looking at himself more realistically after the group experience than before. We think that both these suppositions are true in part. Stanley was attentive to what the others were saying and other studies and observations have shown that such persons gain from the group by vicarious participation.

Group development suffered during the early stages, when the Family Court was being remodeled and expanded, because we had no regular meeting place. Once we met in a section of a large waiting room (all of the sessions took place after the normal working day in the court), where there were occasional interruptions by maintenance personnel. After the building was completed we met in a regular location, isolated and large enough for our group. There was then an improvement in group interaction and also in attendance.

\section{Positive Aspects}

The long-term goal of the experiment was that each group member develop to such a degree that he would no longer engage in delinquent 
acts. During the period in which this group met, none of the boys was referred to court on new charges. In the approximately two and one-half years since the experiment terminated, only one of the members, so far as is known, has become involved in any delinquent conduct; this was of such a minor nature that it was closed with a warning at the preliminary hearing.

Although there is no way of measuring the exact extent of the contribution of the group experience to each member's improvement, we believe that it was significant. The goal of increasing insight and understanding of personal and family problems was unfortunately not measured directly by our testing instruments; however, some of the categories of the Gordon tests indirectly suggested progress in these areas. For example, there was a significant increase in the personal relations category for Robert, Vernon, and James, all of whom had difficulty with their parents. Michael had a similar problem; although he seemed to have regressed slightly in the area of personal relations, he became more responsible. The final testing showed that for most of the group there was improvement in all areas of functioning measured except original thinking. For two of the boys the predominantly negative ratings at the end of the group experience could have been the consequence of the general tendency of the boys to overrate themselves at the beginning of the experiment, although, as mentioned before, mistakes in selection may also have been an important factor. In some of the later group meetings, several members indicated a significant degree of insight into their problems. All members at one time or another made meaningful comments related to their problem areas, and all indicated that they had learned more acceptable ways of working out problems.

Judging from the investigation, we conclude that group counseling is an effective means of meeting the needs of carefully selected delinquents and that it can help a counselor cope with a large caseload. 